Review

\title{
Advanced NMR Approaches for a Detailed Structure Analysis of Natural Products
}

\author{
Eri FukuShI \\ Graduate School of Agriculture, Hokkaido University, Kita-9, Nishi-9, Kita-ku, Sapporo 060-8589, Japan
}

Published August 23, 2006

[doi:10.1271/bbb.50663]

Some new nuclear magnetic resonance (NMR) approaches to elucidate chemical structures, which have not been determined by routine NMR methods, are presented. Selective detection of methine $(\mathrm{CH})$, methylene $\left(\mathrm{CH}_{2}\right)$, or methyl $\left(\mathrm{CH}_{3}\right)$ signals in each subspectrum by editing NMR methods was utilized to reduce the complexity in crowded spectra. It also increased the peak separation and enhanced the sensitivity by limiting the measuring area of the 2D spectra. Several 2D methods to measure ${ }^{2,3} J_{\mathrm{CH}}$ values, which are useful for stereochemical assignment are then introduced. To determine the structure of a highly hydrogen-deficient molecule, efficient correlation methods for long-range ${ }^{13} \mathrm{C}-{ }^{13} \mathrm{C}$ coupling and ${ }^{1} \mathrm{H}-{ }^{15} \mathrm{~N}$ HMBC are also described.

Key words: editing NMR; E-HSQC; E-HSQC-ROESY; DEPT $\mathrm{C}-\mathrm{C}$ relay; natural product

Nuclear magnetic resonance (NMR) spectroscopy is one of the most important instrumental analysis methods for natural products. Routine one-dimensional (1D) and two-dimensional (2D) NMR methods could be used to determine the complex structure of a compound by both an improvement to the hardware and the development of multi-pulse sequences. However, there are still some cases of structural determination not being successful due to the limitations of conventional NMR methods. To solve these problems, some new NMR techniques involving modifications of the conventional methods have been developed. Some of these techniques and their application to the structural analysis of natural products are presented in this paper.

\section{Selective Measurement of the Methine (CH), Methylene $\left(\mathrm{CH}_{2}\right)$, or Methyl $\left(\mathrm{CH}_{3}\right)$ Subspectrum by Editing NMR Methods}

The standard procedure for a structural analysis of natural products involves the carbon multiplicity (methine $(\mathrm{CH}): d$ (doublet); methylene $\left(\mathrm{CH}_{2}\right): t$ (triplet); or methyl $\left(\mathrm{CH}_{3}\right): q$ (quartet)) of each signal from 1D
Table 1. NMR Methods, Key Words, and Related References in This Paper

1D 1 (one)-dimensional

2D $\underline{2}$ (two)- dimensional

2D-DEPT ${ }^{22,23)}$

2D-INEPT ${ }^{21}$

C-C relay ${ }^{70-74)}$ carbon-çarbon relay

COLOC $^{59)}$ correlation via long-range coupling

$\operatorname{COSY}^{36,37)}$ correlated spectroscopy

CT constant time

CT-HMBC ${ }^{34)}$ constant time-HMBC

D-HMBC ${ }^{60)}$ decoupling-HMBC

DEPT $^{1)}$ distortionless enhancement by polarization transfer

DEPT-HMQC ${ }^{7}$

DEPT C-C relay ${ }^{72-74)}$

DEPT-INADEQUATE ${ }^{75,76)}$

$\mathrm{E} \quad$ editing

E-HMQC ${ }^{8)}$

E-HMQC-TOCSY ${ }^{30}$

$\mathrm{E}-\mathrm{HSQC}^{4,9)}$

E-HSQC-NOESY ${ }^{19)}$

E-HSQC-ROESY ${ }^{20)}$

E-HSQC-TOCSY ${ }^{18)}$

$F_{1} \quad \underline{1}$ st frequency domain

$F_{2} \quad$ 2nd frequency domain

gradient-selected multiple quantum filter ${ }^{10}$ )

heteronuclear $\mathrm{NOE}^{83,84)}$

HETLOC $^{42-44)}$ determination of heteronuclear long-range couplings

$\left(=\omega_{1}\right.$ hetero half-filtered TOCSY)

$\mathrm{HMBC}^{6,32,33)}$ heteronuclear multiple bond correlation

$\mathrm{HMQC}^{5,6)}$ heteronuclear multiple quantum coherence

HMQC-NOESY ${ }^{38)}$

HMQC-ROESY ${ }^{39)}$

HMQC-TOCSY ${ }^{4,28,29)}$

$\mathrm{HSQC}^{3,4)} \quad \underline{\text { heteronuclear }}$ single quantum coherence

HSQC-TOCSY ${ }^{4,27)}$

INADEQUATE ${ }^{61-64)}$ incredible natural abundance double quantum transfer experiment

INEPT $^{2}$ insensitive nuclei enhanced by polarization transfer INEPT $\mathrm{C}-\mathrm{C}$ relay ${ }^{70,71)}$

INEPT-INADEQUATE ${ }^{77)}$

$J \quad J$-coupling, scalar coupling

$\mathrm{JBCA}^{\overline{40}} \quad \underline{J}$ based configuration analysis

$J$-HMBC ${ }^{47,48)} \quad J$-resolved HMBC

$J$-IMPEACH MBC ${ }^{46)} J$-resolved improved performance accordion

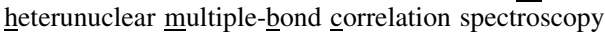

Continued on next page

To whom correspondence should be addressed. Fax: +81-11-716-0879; E-mail: feria@cen.agr.hokudai.ac.jp 
Continued

$J$-res HMBC ${ }^{45)} J$-resolved HMBC

$\mathrm{n}, \mathrm{n}-\mathrm{ADEQUATE}{ }^{67)}$ adequate sensitivity double-quantum

spectroscopy

NMR nuclear magnetic resonance

NOESY ${ }^{13-16)}$ nuclear $\underline{\text { Overhauser }}$ enhancement and exchange

spectroscopy

phase-sensitive $\mathrm{HMBC}^{56}$

ROESY ${ }^{13,17)}$ rotating frame nuclear Overhauser effect spectroscopy

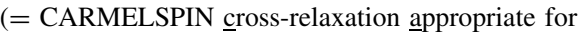
minimolecules emulated by locked spins)

TOCSY ${ }^{11-13)}$ total correlation spectroscopy

(= HOHAHA homonuclear Hartman-Hahn experiment)

${ }^{13} \mathrm{C}-\mathrm{NMR}$ being determined by the $\mathrm{DEPT}^{1)}$ or INEPT $^{2)}$ method. Appropriate setting of the measurement parameters and subsequent addition and/or subtraction with a suitable multiplying coefficient, if necessary, allows DEPT and INEPT experiments to provide each $\mathrm{CH}_{2}$ and $\mathrm{CH}_{3}$-selective subspectrum, and a subspectrum in which $\mathrm{CH}$ and $\mathrm{CH}_{3}$ carbons have a positive phase whereas $\mathrm{CH}_{2}$ carbons have a negative phase. These manipulation processes are referred to as "spectrum editing."

This idea has been extended to the 2D NMR methods to utilize the information of the carbon multiplicity to elucidate the structure of complex molecules and to reduce signal overlap in crowded spectra. 2D HSQC ${ }^{3,4)}$ and $\mathrm{HMQC}^{5,6)}$ spectra are widely used for detecting ${ }^{1} \mathrm{H}-$ ${ }^{13} \mathrm{C}$ correlations directly connected. There are several related methods for the discrimination or selective detection of the $\mathrm{CH}, \mathrm{CH}_{2}$, and $\mathrm{CH}_{3}$ signals by their phases (Fig. 1a) such as DEPT-HMQC, ${ }^{7)} \mathrm{E}$ (editing)HMQC, ${ }^{8)}$ E-HSQC, ${ }^{49}$ ) and gradient-selected multiple quantum filter (MQF). ${ }^{10)}$ Figure 1a shows the E-HSQC spectrum of $\beta$-sitosterol (1), in which the $\mathrm{CH}$ and $\mathrm{CH}_{3}$ signals have a positive phase (drawn by unfilled circles), whereas the $\mathrm{CH}_{2}$ signals have a negative phase (drawn by filled circles). Each $\mathrm{CH}-$ (Fig. 1b), $\mathrm{CH}_{2}$ - (Fig. 1c), and $\mathrm{CH}_{3}$-selective subspectrum can be provided by proper phase cycling and setting the measurement parameters. These methods for discriminating the carbon multiplicity by signal phase and getting subspectra are also called editing methods.

Combining E-HSQC with TOCSY (HOHAHA), ${ }^{11-13)}$ NOESY, ${ }^{13-16)}$ and ROESY ${ }^{13,17)}$ has provided the EHSQC-TOCSY, ${ }^{18)}$ E-HSQC-NOESY, ${ }^{19}$ and E-HSQCROESY ${ }^{20)}$ methods, which have similar advantages to those of E-HSQC. The introduction of editing methods to the traditional ${ }^{13} \mathrm{C}$-observed $2 \mathrm{D}$ methods has also been developed as 2D-INEPT ${ }^{21)}$ and 2D-DEPT. ${ }^{22,23)}$

The subspectrum of E-HSQC, in which the $\mathrm{CH}$ and $\mathrm{CH}_{3}$ signals are positive and the $\mathrm{CH}_{2}$ signals are negative (Fig. 1a), gives information about the one-bond $\mathrm{C}-\mathrm{H}$ correlation and carbon multiplicity at the same time. However, overlapping of signals with opposite phases may cancel the signals. This problem can be avoided by separately measuring each $\mathrm{CH}$ (Fig. 1b) and $\mathrm{CH}_{2}$ subspectrum (Fig. 1c). In Fig. 1a, there are close

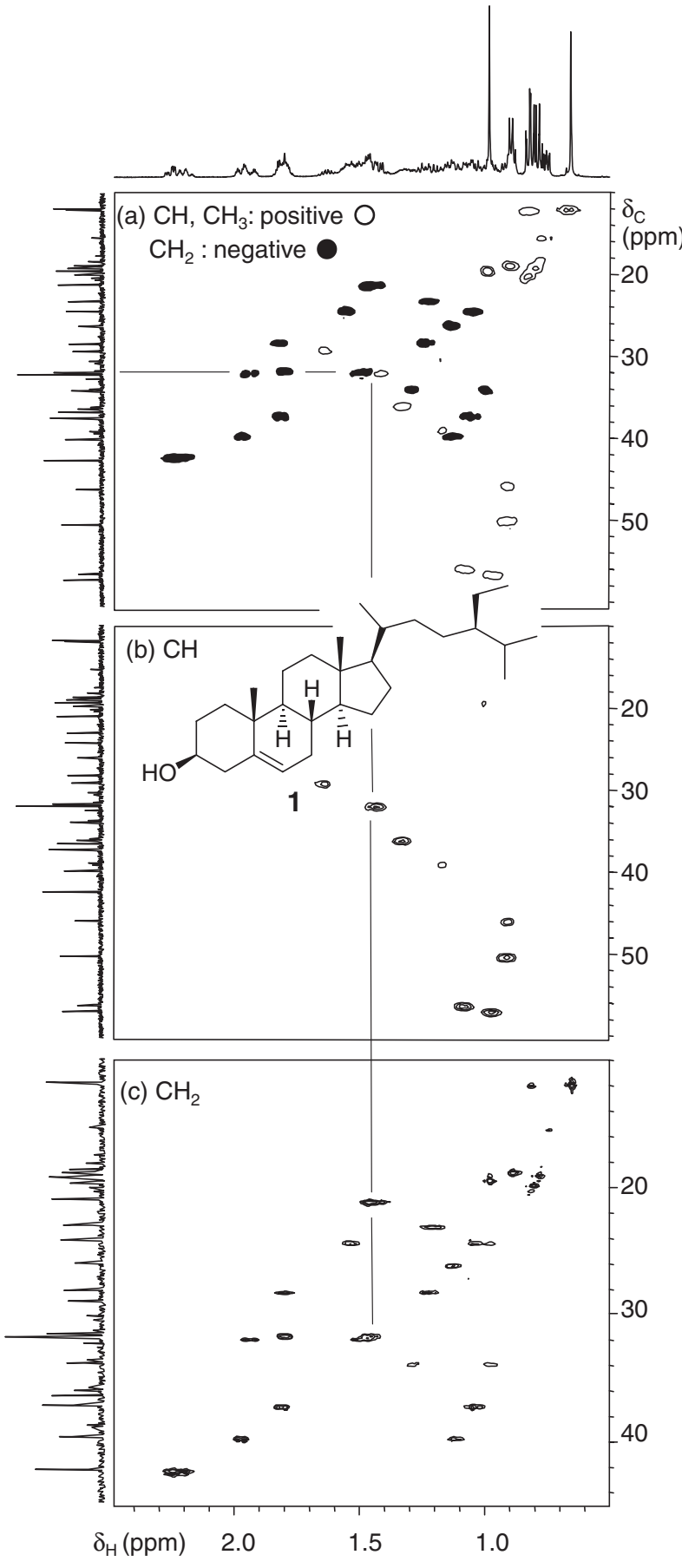

Fig. 1. E-HSQC Spectra of $\beta$-Sitosterol of 1 ( $3 \mathrm{mg} / 0.4 \mathrm{ml}$ of chloroform- $d$ ) Recorded with a Bruker AMX-500 Spectrometer $\left({ }^{1} \mathrm{H}\right.$ at $500 \mathrm{MHz},{ }^{13} \mathrm{C}$ at $125 \mathrm{MHz}$ )

(a) E-HSQC spectrum in which $\mathrm{CH}$ and $\mathrm{CH}_{3}$ signals have a positive phase (drawn by unfilled circles) whereas $\mathrm{CH}_{2}$ signals have a negative phase (drawn by filled circles). (b) $\mathrm{CH}$ subspectrum and (c) $\mathrm{CH}_{2}$ subspectrum. The spectral width and data points were $F_{2}\left({ }^{1} \mathrm{H}\right) 4274 \mathrm{~Hz}$ for 1024 points and $F_{1}\left({ }^{13} \mathrm{C}\right) 19231((\mathrm{a})$ and $(\mathrm{b}))$ and 4808 (c) $\mathrm{Hz}$ for 256 points, respectively. Forward linear prediction in the $F_{1}$ dimension was used to generate the final data matrix, $F_{2}$ $1024 \times F_{1} 512$ point. Multiplication with squared cosine bell windows in both dimensions was performed before Fourier transformation. The number of transients was four, and the total measurement time was $c a .40 \mathrm{~min}$ for each. 


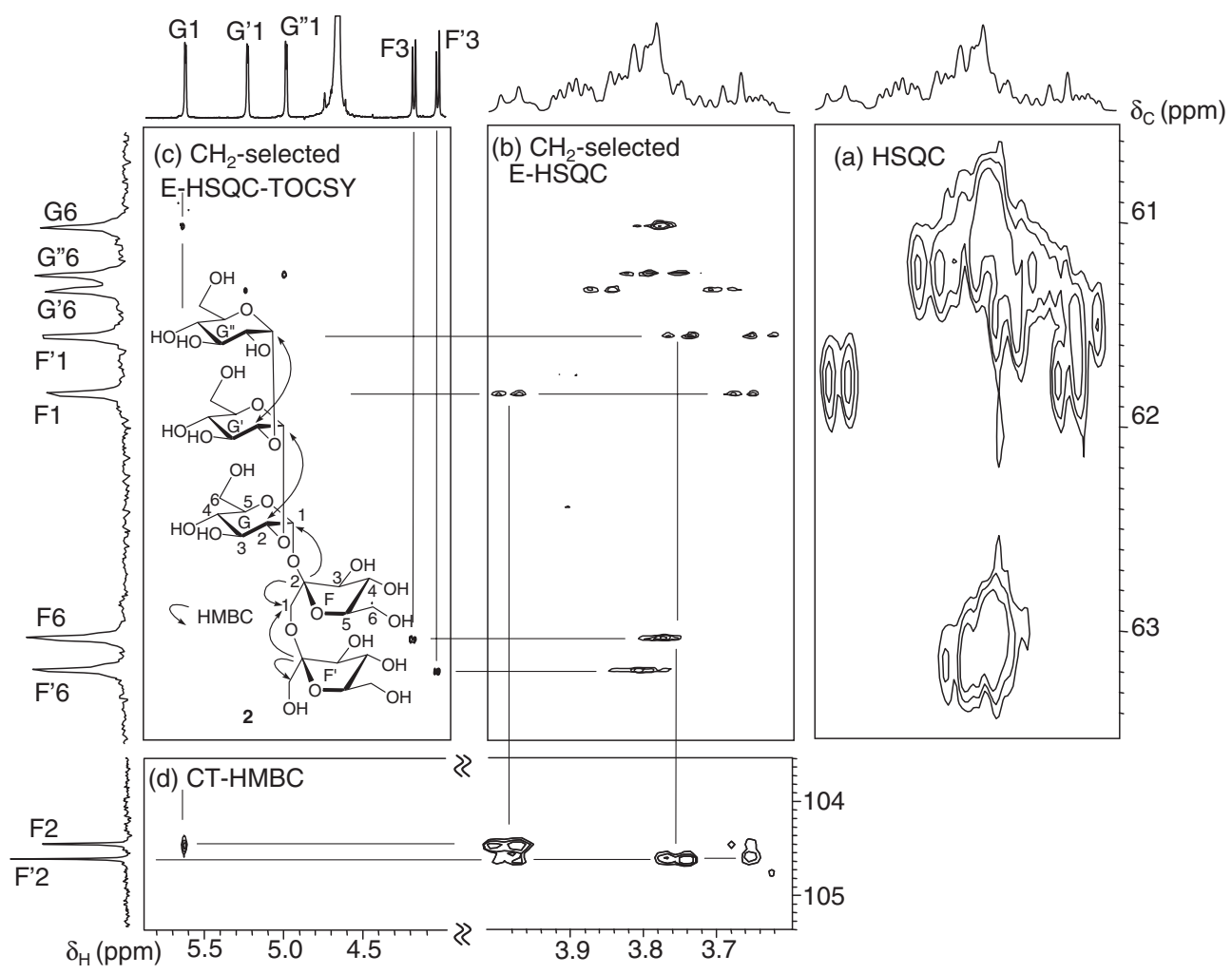

Fig. 2. HSQC, E-HSQC, E-HSQC-TOCSY, and CT-HMBC Spectra for Pentasaccharide $2\left(10.8 \mathrm{mg} / 0.4 \mathrm{ml}\right.$ of $\left.\mathrm{D}_{2} \mathrm{O}\right)$.

(a) Conventional HSQC, (b) $\mathrm{CH}_{2}$-selected E-HSQC, (c) $\mathrm{CH}_{2}$-selected E-HSQC-TOCSY, and (d) CT-HMBC spectra. The spectral width and data points were $F_{2}\left({ }^{1} \mathrm{H}\right) 1623 \mathrm{~Hz}$ for 1024 points and $F_{1}\left({ }^{13} \mathrm{C}\right) 6757$ ((a) and (d)) and 347 ((b) and (c)) $\mathrm{Hz}$ for 512 points, respectively. Forward linear prediction in the $F_{1}$ dimension was used to generate the final data matrix, $F_{2} 1024 \times F_{1} 1024$ ((a) and (d)) and $512($ (b) and (c)) points. Multiplication windows were (a) squared cosine bell in both dimensions, (b) and (c) squared cosine bell in the $F_{2}$ and squared sine bell shifted by $\pi / 6$ in the $F_{1}$ dimension, (d) Lorenz-Gaussian window $(\mathrm{GB}=0.5, \mathrm{LB}=-2)$ in $F_{2}$ and sine bell in the $F_{1}$ dimension. The number of transients and the total measurement time were (a) four and ca. $80 \mathrm{~min}$, (b) 16 and $c a .5 \mathrm{hr}$, (c) 48 and $c a .14 \mathrm{hr}$, and (d) 96 and $c a .27 \mathrm{hr}$.

positive and negative peaks at around $\delta_{\mathrm{C}} 32, \delta_{\mathrm{H}} 1.5 \mathrm{ppm}$. Figures $1 \mathrm{~b}$ and $\mathrm{c}$ reveal these to be the $\mathrm{CH}$ and $\mathrm{CH}_{2}$ signals. It seems that the intensity of the negative peak in Fig. 1a has been weakened by partial cancellation due to overlapping with the stronger positive peak.

Separation into the relevant subspectra is one of the strategies to reduce the complexity of crowded spectra. Another merit of measuring the subspectrum is the enhanced spectral quality. The resolution, one of the key factors of the spectral quality, is defined as spectral width in $\mathrm{Hz}$ per data point: the smaller the value, the higher the resolution. While an increase of $F_{1}\left({ }^{13} \mathrm{C}\right.$ axis $)$ data points is restricted by the experimental time and data size, narrowing the $F_{1}$ spectral width is effective for improving the $F_{1}$ resolution. The $F_{1}$ spectral width for a conventional HSQC spectrum is usually set to cover the range of all protonated carbons. If there are signals outside the $F_{1}$ measuring range, they appear in the spectrum as unwanted folded signals. In respect of EHSQC, the $F_{1}$ spectral width and data points can be optimized for each subspectrum. The chemical shifts of selected carbons for compound $\mathbf{1}$ are limited to a narrow region, enabling the $F_{1}$ spectral range to be set narrower, so that a high $F_{1}$ resolution results as shown in Fig. 1c. HSQC is preferable to HMQC for this high $F_{1}$ resolution subspectrum, since the contribution of proton-proton $J$ coupling $\left(J_{\mathrm{HH}}\right)$ brings about broadening of the correlation peaks in the $F_{1}$ dimension $^{24)}$ and, consequently, lowers the $F_{1}$ peak separation in the latter spectrum.

\section{II. $\mathrm{CH}_{2}$-Selected E-HSQC-TOCSY, a High $F_{1}$ Resolution Subspectrum. Application to the Oligosaccharides}

The NMR spectra of oligosaccharides tend to be too complex to elucidate the structure. The ${ }^{13} \mathrm{C}$ chemical shifts of methylenes, especially, are concentrated in a narrow region, which makes the assignment difficult. This problem has been solved by measuring the highresolution $\mathrm{CH}_{2}$ subspectrum. ${ }^{25)}$ For example, in the HSQC spectra of pentasaccharides $\mathbf{2}^{26)}$ consisting of three units of glucose and two units of fructose, some correlation peaks of eight methylenes were overlapped (Fig. 2a), these were well separated in $\mathrm{CH}_{2}$ subspectrum of E-HSQC (Fig. 2b), enabling the chemical shift of each methylene proton to be assigned. This unambiguous assignment is essential for a determination of the fructosyl linkage between the sugar units.

HSQC-TOCSY $^{4,27)}$ and HMQC-TOCSY, 28,29) are powerful methods for the structural elucidation of 
<smiles>[R]CC/C=C/C(O)C(O)C1OC(C(O)C(O)C(=C)CCC(O)C2CC(O)C(O)C(C(O)C(O)C=C(C)CCC(O)CC(O)C(O)C(O)C(C)C(O)CC=CCC(O)C=CCC(O)CCCC(O)CCCC(O)CO)O2)C(O)C(O)C1O</smiles>

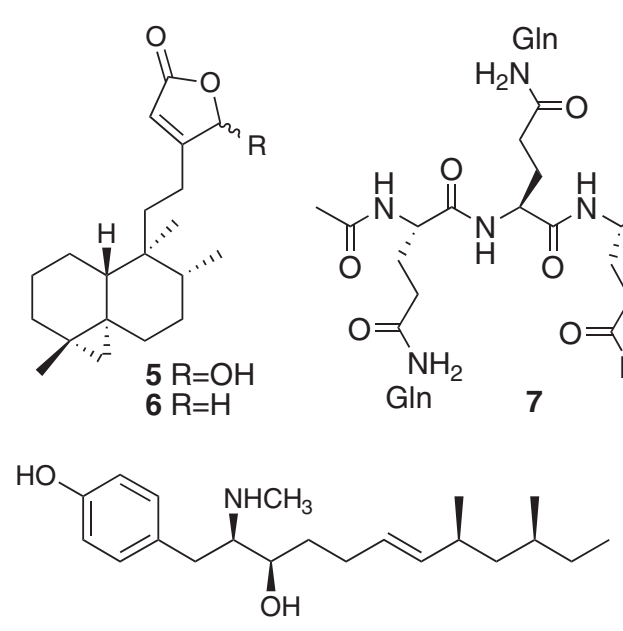

8

$$
\mathrm{O} \approx \mathrm{OH}
$$<smiles>CC[C@H]1CCN(C=O)C1</smiles>

Fig. 3. Chemical Structures of 3-9.

oligosaccharides. In these spectra, a carbon shows correlation signals to its directly attached protons (HSQC or HMQC signal) and to protons in the same spin system with them (HSQC-TOCSY or HMQCTOCSY signals). These spectra of oligosaccharides can be used to distinguish most of the ${ }^{13} \mathrm{C}$ and ${ }^{1} \mathrm{H}$ signals that belong to the same sugar unit. The introduction of editing to these experiments has resulted in the EHMQC-TOCSY ${ }^{30)}$ and E-HSQC-TOCSY methods. The resolution-enhanced $\mathrm{CH}_{2}$-selected E-HSQC-TOCSY spectrum of 2 (Fig. 2c) could distinguish two methylene carbons close to each other. $\mathrm{CH}_{2}$-selected E-HSQC and E-HSQC-TOCSY have been applied to the NMR analysis of several oligosaccharides. ${ }^{18,25,26,31)}$

To detect the glycosidic linkage and assignment of the fructose units, the long-range ${ }^{1} \mathrm{H}-{ }^{13} \mathrm{C}$ correlated spectrum, HMBC, 6,32,33) is necessary. However, with conventional HMBC spectra, the contribution of $J_{\mathrm{HH}}$ coupling brings about broadening of the correlation peaks in the $F_{1}$ dimension like that in the HMQC spectra. This prevents an analysis of the HMBC spectra of oligosaccharides, in which splitting by $J_{\mathrm{HH}}$ is complex and ${ }^{13} \mathrm{C}$ signals are close to one another. In such a case, the CT-HMBC method proposed by Furihata $^{34)}$ is useful. The pulse sequence contains a constant time (CT) for $F_{1}$ chemical shift evolution to suppress $J_{\mathrm{HH}}$ modulation in the $F_{1}$ dimension which results in a sharp line shape in the $F_{1}$ dimension. The correlation peaks in the CT-HMBC spectrum of 2 (Fig. 2d) are well resolved, clarifying the linkage of the sugar units.

The $\mathrm{CH}$ and $\mathrm{CH}_{2}$ subspectrum of E-HSQC, and EHSQC-TOCSY have also been exploited for the spectral analysis of other kinds of complex compounds: luteophanols B (3) and C (4) from a marine dinoflagellate ${ }^{35)}$ possessing many aliphatic methine and methylene carbons, and clerodane-type diterpenes, dytesinins A (5) and $\mathrm{B}(\mathbf{6}),{ }^{19)}$ in which methylene carbons overlap in a narrow region.

\section{Application of the Editing Method to Low-Sensitivity HSQC-ROESY and HSQC- NOESY}

When the ${ }^{1} \mathrm{H}-\mathrm{NMR}$ signals of a compound overlap, it is difficult to analyze them by such homonuclear ${ }^{1} \mathrm{H}-{ }^{1} \mathrm{H}$ correlation methods as COSY, ${ }^{36,37)}$ TOCSY, NOESY, and ROESY. In this case, it is effective to use ${ }^{13} \mathrm{C}$ information by such heteronuclear $2 \mathrm{D} \mathrm{NMR}$ methods as HMQC (or HSQC)-TOCSY and HMQC (or HSQC)-NOESY ${ }^{38)}$ (or ROESY ${ }^{39)}$ ). While HMQCTOCSY and HSQC-TOCSY are widely used, there is only limited application of HMQC (or HSQC)-NOESY (or ROESY) to natural products because of their low sensitivity. NOESY and ROESY experiments are much less sensitive than TOCSY. This problem can be 
(a) HETLOC

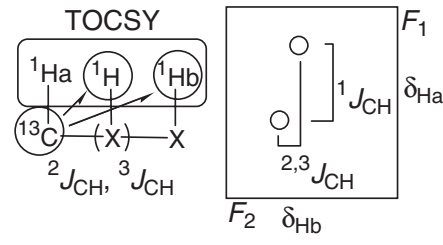

(b) J-resolved HMBC

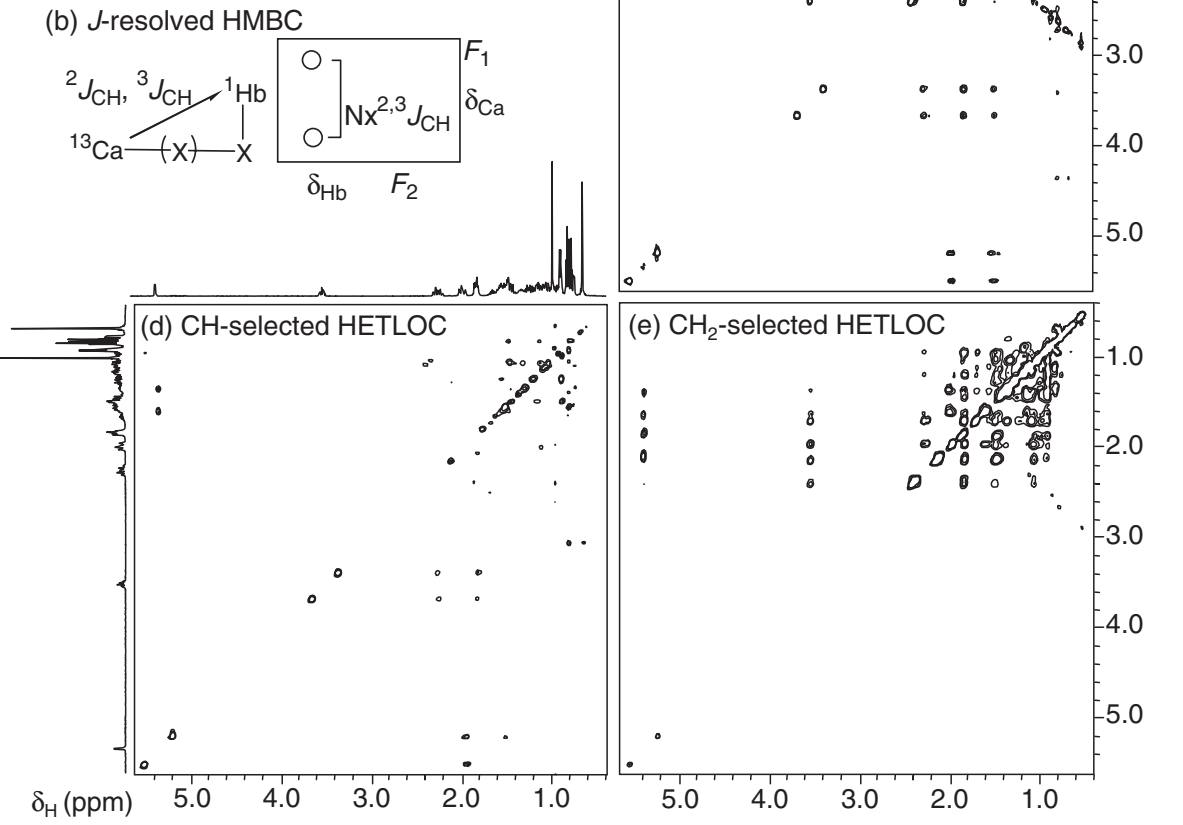

Fig. 4. HETLOC and $J$-Resolved HMBC Spectra of $\mathbf{1}(20 \mathrm{mg} / 0.4 \mathrm{ml}$ of chloroform- $d)$.

(a) and (b) The ${ }^{2,3} J_{\mathrm{CH}}$ values provided by HETLOC and $J$-resolved HMBC spectra. (c) HETLOC, (d) CH-selected HETLOC, and (e) CH${ }_{2}$ selected HETLOC spectra. The spectral widths in both dimensions were $4525 \mathrm{~Hz}$. The data points were $F_{2} 1024 \times F_{1} 256$ points. Zero-filling in the $F_{1}$ dimension was used to generate the final data matrix, $F_{2} 1024 \times F_{1} 512$ point. Multiplication with squared cosine bell windows in both dimensions was performed before Fourier transformation. The number of transients, mixing time of TOCSY, and the total measurement time were respectively $64,70 \mathrm{~ms}$, and $c a$. $7 \mathrm{~h}$ each.

attenuated by using E-HSQC-ROESY and E-HSQCNOESY. These $F_{1}$-limited methods can retain the same $F_{1}$ resolution with a smaller number of $t_{1}$ increments compared to the whole spectrum, since the effect from unwanted folded peaks can be ignored.

The structural analysis of a model peptide of the IgEbinding epitope in the wheat allergen, acetyl-Gln-GlnGln-Pro-Pro (7), has been achieved by using $\mathrm{CH}$ selected E-HSQC-ROESY. Since 7 had only five $\mathrm{CH}$ carbons whose $\delta_{\mathrm{C}}$ values were concentrated in the range of $10 \mathrm{ppm}$, the $F_{1}$ spectral width and data points could be reduced. As a result, the $\mathrm{CH}$ subspectrum with a sufficient signal-to-noise ratio revealed the configuration of the backbone amide bonds to be all-trans. ${ }^{20)}$

CH-selected E-HSQC-NOESY has been measured for a determination of the relative stereochemistry of dytesinin A (5) from a marine tunicat. Since $\mathbf{5}$ contained only four methine carbons whose chemical shifts were relatively separated, a reduction of the $F_{1}$ data points to 16 and an increase in the number of transients provided a sufficient signal-to-noise ratio. ${ }^{19)}$

\section{Application of Long-Range Coupling Constants for Determining Stereochemistry}

Two- and three-bond coupling constants between protons or a proton and carbon show the dependence on their stereochemistry. Determination of the relative configuration by ${ }^{3} J_{\mathrm{HH}}$ and ${ }^{2,3} J_{\mathrm{CH}}$ has been developed as a $J$-based configuration analysis (JBCA). ${ }^{40)}$ Among the many $2 \mathrm{D}$ methods available for measuring ${ }^{2,3} J_{\mathrm{CH}},{ }^{41)}$ the simplest and the most approproate experiments for JBCA are HETLOC ${ }^{42-44)}$ and $J$-resolved HMBC ${ }^{45-48)}$ which provide the magnitude of ${ }^{2,3} J_{\mathrm{CH}}$ values directly from the spectra. The HETLOC spectrum is based on TOCSY. It has both $F_{1}$ and $F_{2}{ }^{1} \mathrm{H}$-chemical shift dimensions. The diagonal and the correlation peaks are doublets split by ${ }^{1} J_{\mathrm{CH}}$ in the $F_{1}$ dimension. The longrange $J_{\mathrm{CH}}\left({ }^{\mathrm{LR}} J_{\mathrm{CH}}\right)$ values are measured from the signal displacement of each signal of the cross-peak doublet. This is a powerful method to measure the ${ }^{\mathrm{LR}} J_{\mathrm{CH}}$ values between ${ }^{1} \mathrm{H}$ and ${ }^{13} \mathrm{C}$ in the same ${ }^{1} \mathrm{H}$-spin network (Fig. 4a). 
There are some variants of $J$-resolved HMBC: $J$-res $\mathrm{HMBC}^{45)} J$-IMPEACH $\mathrm{MBC},{ }^{46)}$ and $J$-HMBC. ${ }^{47,48)}$ These provide spectra like HMBC. The HMBC correlation peaks in these spectra are split in the $F_{1}$ dimension by multiplied ${ }^{\mathrm{LR}} J_{\mathrm{CH}}$ with the $J$-scaling factor, $N$ (Fig. 4b). The ${ }^{\mathrm{LR}} J_{\mathrm{CH}}$ values between ${ }^{1} \mathrm{H}$ and ${ }^{13} \mathrm{C}$ via quaternary carbons or heteronuclei and the ${ }^{\mathrm{LR}} J_{\mathrm{CH}}$ values on quaternary carbons are measurable by these methods. Scaling factor $N$ is set according to the objective ${ }^{\mathrm{LR}} J_{\mathrm{CH}}$ value as $N>1 /\left({ }^{\mathrm{LR}} J_{\mathrm{CH}} \times t_{1 \max }\right)$. Setting a large $N$ value results in sensitivity loss. In respect of HETLOC, the intervention of a small $J_{\mathrm{HH}}$ value weakens the peak intensity, and the ${ }^{\mathrm{LR}} J_{\mathrm{CH}}$ values between ${ }^{1} \mathrm{H}$ and ${ }^{13} \mathrm{C}$ via quaternary carbons and ${ }^{\mathrm{LR}} J_{\mathrm{CH}}$ values on quaternary carbons cannot be obtained. Those methods are therefore used complementarily. The benefits of editing are also utilized for HETLOC. ${ }^{49-51)}$ Measurement of the subspectrum according to the carbon multiplicity of HETLOC is helpful for reducing signal overlapping. Figures $4 \mathrm{c}$, d, and e show conventional, $\mathrm{CH}-$, and $\mathrm{CH}_{2}-$ selected HETLOC spectra of $\mathbf{1}$, respectively. The $\mathrm{CH}$ and $\mathrm{CH}_{2}$ protons are respectively selected in the $F_{1}$ dimension of each subspectrum d and e. 1D variants of HETLOC $^{52-54)}$ have also been reported which provide two 1D spectra corresponding to the two $F_{1}$ slices (parallel to the $F_{2}$ axis) through each signal of the crosspeak doublet of HETLOC.

Early applications of $\mathrm{JBCA}^{55)}$ used HETLOC and phase-sensitive $\mathrm{HMBC}^{56)}$ to measure ${ }^{2,3} J_{\mathrm{CH}}$. In the latter spectrum, ${ }^{2,3} J_{\mathrm{CH}}$ values were determined by calculation of the intensity of the cross peaks. In later years, $J$-resolved HMBC methods were developed, and have been applied to the structural analysis of dytesinin A $(\mathbf{5}),{ }^{20)}$ tyroscherin $(\mathbf{8}),{ }^{57)}$ and lycoposerramine-B (9). ${ }^{58)}$

\section{Structural Determination of a Highly Hydrogen-Deficient Molecule: Application of Super-Long-Range Correlation between a Proton and Carbon via Four Bonds and Measuring the Long-Range ${ }^{13} \mathrm{C}-{ }^{13} \mathrm{C}$ Cou- pling Constants}

The structural elucidation of highly hydrogen-deficient molecules might be a problem because the carbon network of such molecules cannot be completely followed by heteronuclear long-range $\mathrm{C}-\mathrm{H}$ correlation spectroscopy, such as $\mathrm{HMBC}$ and COLOC ${ }^{59)}$ which usually detect the long-range $J$ coupling between a proton and carbon connected via three or less bonds. Several approaches have been reported to detect small ${ }^{\mathrm{n}} J_{\mathrm{CH}}(\mathrm{n}>3)$ or magnetization transfer via ${ }^{\mathrm{n}} J_{\mathrm{CC}}$ for the structural elucidation of such compounds. An example of the former is decoupling (D)-HMBC, ${ }^{60)}$ while the latter can be detected by conventional INADEQUATE $^{61,62)}$ or its gradient-selected version ${ }^{63,64)}$ by optimizing for the observation of small ${ }^{\mathrm{n}} J_{\mathrm{CC}}$. Improve- ments to INADEQUATE and related methods have been reviewed by Buddrus. ${ }^{65,66)}$ The most serious shortcoming with these methods is the low sensitivity resulting from the low natural abundance of the isotopomer to be detected which has two ${ }^{13} \mathrm{C}$ nuclei in a molecule. The sensitivity can be enhanced by several strategies including ${ }^{1} \mathrm{H}$ detection such as $2 \mathrm{D} \mathrm{n}, \mathrm{n}$-ADEQUATE, ${ }^{67}$ using composite ${ }^{68,69)}$ pulses, magnetization transfer from ${ }^{1} \mathrm{H}$, and elimination of the double-quantum filtration $\left(\mathrm{C}-\mathrm{C}\right.$ relay) ${ }^{70-74)}$ The methods combined with magnetization transfer from ${ }^{1} \mathrm{H}$ have resulted in two-step magnetization transfer via ${ }^{1} J_{\mathrm{CH}} \rightarrow{ }^{\mathrm{n}} J_{\mathrm{CC}}$ such as DEPTINADEQUATE, ${ }^{75,76)}$ INEPT-INADEQUATE ${ }^{77)}$ DEPT $\mathrm{C}-\mathrm{C}$ relay, ${ }^{72-74)}$ and INEPT $\mathrm{C}-\mathrm{C}$ relay. ${ }^{70,71)}$ The $1 \mathrm{D}$ methods ${ }^{70-72,75-77)}$ are the most advantageous from the viewpoint of the sensitivity. A signal overlapping problem arising from more than one correlation at the observed carbon can be resolved by measuring each subspectrum by DEPT-INADEQUATE, INEPTINADEQUATE, DEPT $\mathrm{C}-\mathrm{C}$ relay, and INEPT $\mathrm{C}-\mathrm{C}$ relay.

In respect of khellin (10), only the connectivity represented by the bold line in Fig. 5 can be traced by $\mathrm{HMBC}$, and hence, the direction of the $\gamma$-pyrone ring fused to the benzofuran ring cannot be determined. In the $\mathrm{CH}$ subspectrum from the DEPT long-range $\mathrm{C}-\mathrm{C}$ relay method, two sets of doublets, $J=11.8$ and $3.1 \mathrm{~Hz}$, were clearly observed at C-4a, which would have been derived from two- and three-bond coupling with C-6 and C-3, respectively. Hence, the regiochemical connectivity between the $\gamma$-pyrone and benzofuran rings could be unambiguously determined. ${ }^{74)}$ The assignment of the acylated position of phenols is also a problem, since acyl protons located in a four-bond position away from the attached acyloxy carbons. In respect of methyl 3,4diacetoxycinnamate (11), two acyl groups were assigned by the 2D DEPT long-range $\mathrm{C}-\mathrm{C}$ relay method, in which key correlation peaks between the acyl protons and oxygenated benzene carbons indicated by arrows in the chemical structure were obtained. ${ }^{78)}$ The structural elucidation of 16-membered macrodiolide amphidinolide $\mathrm{X}(\mathbf{1 2})\left(\mathrm{ca} .5 \%{ }^{13} \mathrm{C}\right.$ enriched) isolated from a marine dinoflagellate showed that two ester linkages could not be determined from the HMBC spectrum because of the lack of correlation peaks between two ester carbonyl carbons and H-10 and H-17. However, the 2D DEPT long-range $\mathrm{C}-\mathrm{C}$ relay spectrum gave correlation peaks for $\mathrm{C}-16 / \mathrm{C}-1$ and $\mathrm{C}-10 / \mathrm{C}-6$, resulting in the total structure of 12 shown in Fig. 5. ${ }^{79)}$

${ }^{1} \mathrm{H}-{ }^{15} \mathrm{~N}$ HMBC is useful for compounds containing nitrogen in the molecule. Due to the low natural abundance and low gyromagnetic ratio of ${ }^{15} \mathrm{~N}$, direct ${ }^{15} \mathrm{~N}$ observation is very difficult at the natural abundance level. The advent of the inverse-detected method coupled with a pulsed-field-gradient has resulted in ${ }^{1} \mathrm{H}-{ }^{15} \mathrm{~N}$ long-range heteronuclear correlation spectroscopy becoming practical at the level of natural abundance. ${ }^{80,81)}$ 


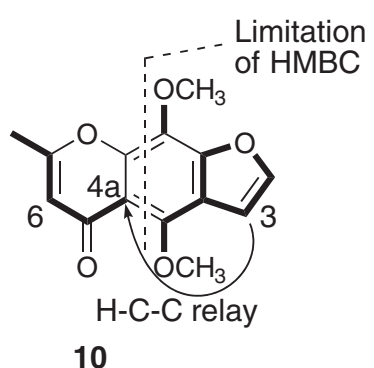

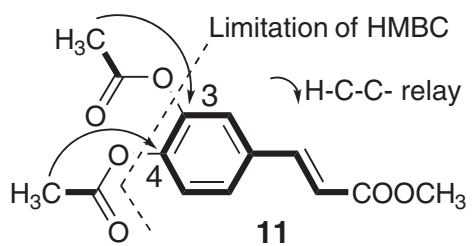

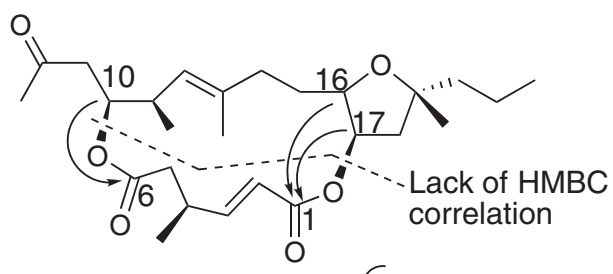

12

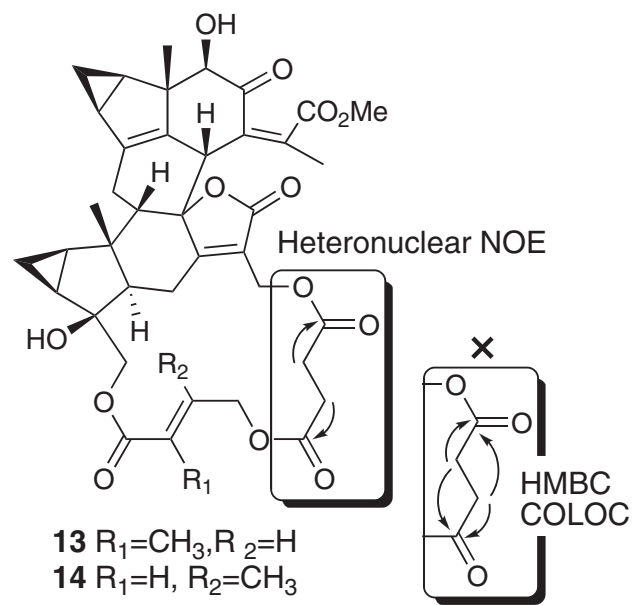

Fig. 5. Chemical Structures of 10-14.

\section{Discrimination of ${ }^{2} J_{\mathrm{CH}}$ and ${ }^{3} J_{\mathrm{CH}}$ Corre- lations}

Shizukaols B (13) and F (14), characteristic dimers from Chloranthus japonicus, ${ }^{82)}$ have a pendant macrocyclic ester substructure consisting of $\gamma$-hydroxytiglic or $\gamma$-hydroxysenecionic acid, and succinic or malic acid, respectively. Some problems may arise in the structural analysis of these compounds since an ester linkage separates the $\mathrm{C}-\mathrm{C}$ connectivity in such a pendant ring. Two pairs of methylene protons in the succinate residue could not be unambiguously assigned by detecting ${ }^{\mathrm{LR}} J_{\mathrm{CH}}$, since all the protons in two methylenes were correlated with both carbonyl carbons in the HMBC and COLOC spectra as shown in Fig. 5. Heteronuclear $\mathrm{NOE}^{83,84)}$ was found effective to selectively detect the two-bond ${ }^{1} \mathrm{H}-\mathrm{X}-{ }^{13} \mathrm{C}(\mathrm{X}=\mathrm{C}$ or heteroatom) connectivity. ${ }^{85)} \mathrm{NOE}$ from the two protons of each methylene was observed on the neighboring carbonyl carbon. These results revealed the assignment of the two methylenes in the succinate residue. If the objective two-bond correlation is that between a proton and protonated carbon, there are several methods to discriminate ${ }^{2} J_{\mathrm{CH}}$ and ${ }^{3} J_{\mathrm{CH}}$ by using $J_{\mathrm{HH}} \cdot{ }^{86-88)}$

The sensitivity of NMR spectroscopy has been dramatically improved in recent years by the development of superconducting cryogenic probeheads ${ }^{89}$ ) and high-field magnets. The other factor for enhancing sensitivity is to reduce the sample volume by concentrating the solution. A variety of micro- and submicroprobes of less than $5 \mathrm{~mm}$ in diameter ${ }^{90)}$ are commercially available. Combined use of such probes with Shigemi NMR micro cells ${ }^{91,92)}$ achieves a further reduction in the sample volume.

NMR spectroscopy has become a daily tool. Routine experiments can provide high-quality spectra more easily due to the improved hardware and software now available. Structural elucidation of many compounds therefore demands less time than before. However, there are still some structural problems which require unique approaches to overcome the limitations of the conventional NMR methods. NMR provides various information by tailored pulse sequences which comprise pulses and delay times. Since the combination of pulses and delays is infinite, NMR would satisfy the present and future needs for new methods.

\section{Acknowledgments}

I thank Professors Satoshi Tahara, Akitami Ichihara, and Junya Mizutani (successive chairpersons of the committee for the GC-MS \& NMR Laboratory, Graduate School of Agriculture, Hokkaido University) for kindly permitting me to carry out this study. I also thank Professor Jun Kawabata (Graduate School of Agriculture, Hokkaido University) for teaching me about NMR, express my gratitude to colleagues. I thank Professor Toshifumi Hiraoki (Graduate School of Engineering, Hokkaido University) and Dr. Misako Imachi (Bruker Biospin) for technical advice on NMR pulse sequences, and all the NMR researchers for useful discussions.

\section{References}

1) Bendall, M. R., Doddrell, D. M., and Pegg, D. T., Editing of ${ }^{13} \mathrm{C}$ NMR spectra. A pulse sequence for the generation of subspectra. J. Am. Chem. Soc., 103, 46034605 (1981). 
2) Morris, G. A., and Freeman, R., Enhancement of nuclear magnetic resonance signals by polarization transfer. $J$. Am. Chem. Soc., 101, 760-762 (1979).

3) Bodenhausen, G., and Ruben, D. J., Natural abundance nitrogen-15 NMR by enhanced heteronuclear spectroscopy. Chem. Phys. Lett., 69, 185-189 (1980).

4) Willker, W., Leibfritz, D., Kerssebaum, R., and Bermel, W., Gradient selection in inverse heteronuclear correlation spectroscopy. Magn. Reson. Chem., 31, 287-292 (1993).

5) Müller, L., Sensitivity enhanced detection of weak nuclei using heteronuclear multiple quantum coherence. J. Am. Chem. Soc., 101, 4481-4484 (1979).

6) Hurd, R. E., and John, B. K., Gradient-enhanced protondetected heteronuclear multiple-quantum coherence spectroscopy. J. Magn. Reson., 91, 648-653 (1991).

7) Kessler, H., Schmieder, P., and Kurz, M., Implementation of the DEPT sequence in inverse shift correlation: the DEPT-HMQC. J. Magn. Reson., 85, 400-405 (1989).

8) Zhang, X., and Wang, C., ${ }^{1} \mathrm{H}$-detected editable heteronuclear multiple-quantum correlation experiment at natural abundance. J. Magn. Reson., 91, 618-623 (1991).

9) Davis, D. G., Improved multiplet editing of protondetected, heteronuclear shift-correlation spectra. $J$. Magn. Reson., 91, 665-672 (1991).

10) Parella, T., Sánchez-Ferrando, F., and Virgili, A., Clean proton editing using a gradient-selected multiple-quantum filter. J. Magn. Reson., A117, 78-83 (1995).

11) Braunschweiler, L., and Ernst, R. R., Coherence transfer by isotropic mixing: application to proton correlation spectroscopy. J. Magn. Reson., 53, 521-528 (1983).

12) Hurd, R. E., Gradient-enhanced spectroscopy. J. Magn. Reson., 87, 422-428 (1990).

13) Parella, T., Sánchez-Ferrando, F., and Virgili, A., Quick recording of pure absorption 2D TOCSY, ROESY, and NOESY spectra using pulsed field gradients. J. Magn. Reson., 125, 145-148 (1997).

14) Jeener, J., Meier, B. H., Bachmann, P., and Ernst, R. R., Investigation of exchange process by two-dimensional NMR spectroscopy. J. Chem. Phys., 71, 4546-4563 (1979).

15) States, D. J., Haberkorn, R. A., and Ruben, D. J., A twodimensional nuclear Overhauser experiment with pure absorption phase in four quadrants. J. Magn. Reson., 48, 286-292 (1982).

16) Wagner, R., and Berger, S., Gradient-selected NOESY. A fourfold reduction of measurement time for the NOESY experiment. J. Magn. Reson., A123, 119-121 (1996).

17) Bothner-By, A. A., Stephens, R. L., Lee, J.-M., Warren, C. D., and Jeanloz, R. W., Structure determination of a tetrasaccharide: transient nuclear Overhauser effects in the rotating frame. J. Am. Chem. Soc., 106, 811-813 (1984).

18) Yamamori, A., Fukushi, E., Onodera, S., Kawabata, J., and Shiomi, N., NMR analysis of mono-and difructosyllactosucrose synthesized by $1^{\mathrm{F}}$-fructosyltransferase purified from roots of asparagus (Asparagus officinalis L.). Magn. Reson. Chem., 40, 541-544 (2002).

19) Shimbo, K., Tsuda, M., Fukushi, E., Kawabata, J., and Kobayashi, J., Dytesinins A and B, new clerodane-type diterpenes with a cyclopropane ring from the tunicate Cystodytes sp. Tetrahedron, 56, 7923-7926 (2000).
20) Fukushi, E., Tanabe, S., Watanabe, M., and Kawabata, J., NMR analysis of a model pentapeptide, acetyl-GlnGln-Gln-Pro-Pro, as an epitope of wheat allergen. Magn. Reson. Chem., 36, 741-746 (1998).

21) Bax, A., and Morris, G. A., An improved method for heteronuclear chemical shifts correlation by two-dimensional NMR. J. Magn. Reson., 42, 501-505 (1981).

22) Bendall, M. R., and Pegg, D. T., ${ }^{1} \mathrm{H}-{ }^{13} \mathrm{C}$ two-dimensional chemical shift correlation spectroscopy using DEPT. J. Magn. Reson., 53, 144-148 (1983).

23) Pegg, D. T., and Bendall, M. R., Two-dimensional DEPT NMR spectroscopy. J. Magn. Reson., 55, 114-127 (1983).

24) Bax, A., Ikura, M., Kay, L. E., Torchia, D. A., and Tschudin, R., Comparison of different modes of twodimensional reverse-correlation NMR for the study of proteins. J. Magn. Reson., 86, 304-318 (1990).

25) Fukushi, E., Onodera, S., Yamamori, A., Shiomi, N., and Kawabata, J., NMR analysis of tri-and tetrasaccharides from asparagus. Magn. Reson. Chem., 38, 1005-1011 (2000).

26) Okada, H., Fukushi, E., Onodera, S., Nishimoto, T., Kawabata, J., Kikuchi, M., and Shiomi, N., Synthesis and structural analysis of five novel oligosaccharides prepared by glucosyl transfer from $\beta$-D-glucose 1 phosphate to isokestose and nystose using Thermoanaerobacter brockii kojibiose phosphorylase. Carbohydr. Res., 338, 879-885 (2003).

27) Domke, T., A new method to distinguish between direct and remote signals in proton-relayed $\mathrm{X}, \mathrm{H}$ correlations. J. Magn. Reson., 95, 174-177 (1991).

28) Lerner, L., and Bax, A., Sensitivity-enhanced twodimensional heteronuclear relayed coherence transfer NMR spectroscopy. J. Magn. Reson., 69, 375-380 (1986).

29) Martin, G. E., Spitzer, T. D., Crouch, R. C., Luo, J.-K., and Castle, N., Inverted and suppressed direct response HMQC-TOCSY spectra. A convenient method of spectral editing. J. Heterocyclic Chem., 29, 577-582 (1992).

30) Crouch, R. C., Spitzer, T. D., and Martin, G. E., Strategies for the phase editing of relayed responses in 2D HMQC-TOCSY spectra. Magn. Reson. Chem., 30, S71-S73 (1992).

31) Takahashi, N., Okada, H., Fukushi, E., Onodera, S., Nishimoto, T., Kawabata, J., and Shiomi, N., Structural analysis of six novel oligosaccharides synthesized by glucosyl transfer from $\beta$-D-glucose 1-phosphate to raffinose and stachyose using Thermoanaerobacter brockii kojibiose phosphorylase. Tetrahedron: Asymmetry, 16, 57-63 (2005).

32) Bax, A., and Summers, M. F., ${ }^{1} \mathrm{H}$ and ${ }^{13} \mathrm{C}$ assignments from sensitivity-enhanced detection of heteronuclear multiple-bond connectivity by 2D multiple quantum NMR. J. Am. Chem. Soc., 108, 2093-2094 (1986).

33) Summers, M. F., Marzilli, L. G., and Bax, A., Complete ${ }^{1} \mathrm{H}$ and ${ }^{13} \mathrm{C}$ assignments of coenzyme $\mathrm{B}_{12}$ through the use of new two-dimensional NMR experiments. J. Am. Chem. Soc., 108, 4285-4294 (1986).

34) Furihata, K., and Seto, H., Constant time HMBC (CTHMBC), a new HMBC technique useful for improving separation of cross peaks. Tetrahedron Lett., 39, 73377340 (1998).

35) Kubota, T., Tsuda, M., Doi, Y., Takahashi, A., 
Nakamichi, H., Ishibashi, M., Fukushi, E., Kawabata, J., and Kobayashi, J., Luteophanols B and C, new polyhydroxyl compounds from marine dinoflagellate Amphidinium sp. Tetrahedron, 54, 14455-14464 (1998).

36) Aue, W. P., Batholdi, E., and Ernst, R. R., Twodimensional spectroscopy. Application to nuclear magnetic resonance. J. Chem. Phys., 64, 2229-2246 (1975).

37) von Kienlin, M., Moonen, C. T. W., van der Toorn, A., and van Zijl, P. C. M., Rapid recording of solventsupressed 2D COSY spectra with inherent quadrature detection using pulsed field gradients. J. Magn. Reson., 93, 423-429 (1991).

38) Kawabata, J., Fukushi, E., and Mizutani, J., Symmetric sesquiterpene dimer from Chloranthus serratus. Phytochemistry, 32, 1347-1349 (1993).

39) Kawabata, J., Fukushi, E., and Mizutani, J., 2D ${ }^{13}$ Ccoupled HMQC-ROESY: a probe for NOEs between equivalent protons. J. Am. Chem. Soc., 114, 1115-1117 (1992).

40) Matsumori, N., Kaneno, D., Murata, M., Nakamura, H., and Tachibana, K., Stereochemical determination of acyclic structures based on carbon-proton spin-coupling constants. A method of configuration analysis for natural products. J. Org. Chem., 64, 866-876 (1999).

41) Marquez, B. L., Gerwick, W. H., and Williamson, R. T., Survey of NMR experiments for the determination of ${ }^{\mathrm{n}} J(\mathrm{C}, \mathrm{H})$ heteronuclear coupling constants in small molecules. Magn. Reson. Chem., 39, 499-530 (2001).

42) Kurz, M., Schmieder, P., and Kessler, H., HETLOC, an efficient method for determining heteronuclear longrange couplings with heteronuclei in natural abundance. Angew. Chem. Int. Ed. Engl., 30, 1329-1331 (1991).

43) Wollborn, U., and Leibfritz, D., Measurement of heteronuclear long-range coupling constants from inverse homonuclear 2D NMR spectra. J. Magn. Reson., 98, 142-146 (1992).

44) Uhrín, D., Batta, G., Hruby, V. J., Barlow, P. N., and Kövér, K. E., Sensitivity- and gradient-enhanced hetero $\left(\omega_{1}\right)$ half-filtered TOCSY experiment for measuring long-range heteronuclear coupling constants. J. Magn. Reson., 130, 155-161 (1998).

45) Furihata, K., and Seto, H., J-resolved HMBC, a new NMR technique for measuring heteronuclear long-range coupling constants. Tetrahedron Lett., 40, 6271-6275 (1999).

46) Williamson, R. T., Marquez, B. L., Gerwick, W. H., Martin, G. E., and Krishnamurthy, V. V., J-IMPEACHMBC: a new concatenated NMR experiment for $F_{1}$ scalable, J-resolved HMBC. Magn. Reson. Chem., 39, 127-132 (2001).

47) Gotfredsen, C. H., Meissner, A., Duus, J. Ø., and Sørensen, O. W., New methods for measuring ${ }^{1} \mathrm{H}-{ }^{31} \mathrm{P}$ coupling constants in nucleic acids. Magn. Reson. Chem., 38, 692-695 (2000).

48) Meissner, A., and Sørensen, O. W., Measurement of $J(\mathrm{HH})$ and long-range $J(\mathrm{X}, \mathrm{H})$ coupling constants in small molecules. Broadband XLOC and $J$-HMBC. Magn. Reson. Chem., 39, 49-52 (2001).

49) Wollborn, U., and Leibfritz, D., Inverse editing of protons in two-dimensional homonuclear and heteronuclear relayed COSY spectra. Magn. Reson. Chem., 29, 238-243 (1991).

50) Willker, W., Wollborn, U., and Leibfritz, D., Exact measurement of ${ }^{3} J_{\mathrm{CH}}$ coupling constants using protondetected editing and selection sequence. J. Magn. Reson., B101, 83-86 (1993).

51) Stelten, J., and Leibfritz, D., Clean $\mathrm{HX}$ and $\mathrm{H}_{2} \mathrm{X}$ proton selection using gradients: gs $\mathrm{H}_{\mathrm{n}} \mathrm{X}$-HYSEL. Magn. Reson. Chem., 34, 951-954 (1996).

52) Fukushi, E., and Kawabata, J., Heteronuclear long-range couplings from displacement of signals in two 1D subspectra. J. Magn. Reson., A108, 103-105 (1994).

53) Bazzo, R., Barbato, G., and Cicero, D. O., Accurate measurement of heteronuclear long-range coupling constants from 1D subspectra in crowded spectral regions. J. Magn. Reson., A117, 267-271 (1995).

54) Yang, D., and Nagayama, K., A sensitivity-enhanced method for measuring heteronuclear long-range coupling constants from the displacement of signals in two 1D subspectra. J. Magn. Reson., A118, 117-121 (1996).

55) Matsumori, N., Murata, M., and Tachibana, K., Conformational analysis of natural products using longrange carbon-proton coupling constants: three-dimensional structure of okadaic acid in solution. Tetrahedron, 51, 12229-12238 (1995).

56) Davis, D. G., Proton NMR detection of long-range heteronuclear multiquantum coherences in proteins: the complete assignment of the quaternary aromatic ${ }^{13} \mathrm{C}$ chemical shifts in lysozyme. J. Am. Chem. Soc., 111, 5466-5468 (1989).

57) Hayakawa, Y., Yamashita, T., Mori, T., Nagai, K., Shin-ya, K., and Watanabe, H., Structure of tyroscherin, an antitumor antibiotic against IGF-1-dependent cells from Pseudallesheria sp. J. Antibiotics, 57, 634-638 (2004).

58) Katakawa, K., Kitajima, M., Aimi, N., Seki, H., Yamaguchi, K., Furihata, K., Harayama, T., and Takayama, H., Structure elucidation and synthesis of lycoposerramine-B, a novel oxime-containing Lycopodium alkaloid from Lycopodium serratum Thunb. J. Org. Chem., 70, 658-663 (2005).

59) Kessler, H., Griesinger, C., Zarbock, J., and Loosli, H. R., Assignment of carbonyl carbons and sequence analysis in peptides by heteronuclear shift correlation via small coupling constants with broadband decoupling in $t_{1}$ (COLOC). J. Magn. Reson., 57, 331-336 (1984).

60) Furihata, K., and Seto, H., Decoupled HMBC (DHMBC), an improved technique of HMBC. Tetrahedron Lett., 36, 2817-2820 (1995).

61) Bax, A., Freeman, R., and Frenkiel, T. A., An NMR technique for tracing the carbon skeleton of an organic molecule. J. Am. Chem. Soc., 103, 2102-2104 (1981).

62) Turner, D. L., Carbon-13 autocorrelateion NMR using double-quantum coherence. J. Magn. Reson., 49, 175178 (1982).

63) Koshino, H., and Uzawa, J., PFG-INADEQUATE for detection of two and three bond ${ }^{13} \mathrm{C}-{ }^{13} \mathrm{C}$ couplings. Bull. Magn. Reson., 17, 260-261 (1995).

64) Willker, W., and Leibfritz, D., Gradient selection of coherences in experiments with carbon detection. Magn. Reson. Chem., 32, 665-669 (1994).

65) Buddrus, J., and Bauer, H., Direct identification of the carbon skeleton of organic compounds using double quantum coherence ${ }^{13} \mathrm{C}$-NMR spectroscopy. The INADEQUATE pulse sequence. Angw. Chem. Int. Ed. Engl., 26, 625-642 (1987). 
66) Buddrus, J., and Lambert, J., Connectivities in molecules by INADEQUATE: recent developments. Magn. Reson. Chem., 40, 3-23 (2002).

67) Reif, B., Köck, M., Kerssebaum, R., Kang, H., Fenical, W., and Griesinger, C., ADEQUATE, a new set of experiments to determine the constitution of small molecules at natural abundance. J. Magn. Reson., A118, 282-285 (1996).

68) Levitt, M. H., and Ernst, R. R., Improvement of pulse performance in NMR coherence transfer experiments. A compensated INADEQUATE experiment. Mol. Phys., 50, 1109-1124 (1983).

69) Torres, A. M., Nakashima, T. T., McClung, R. E. D., and Muhandiram, D. R., Improvement of INADEQUATE using compensated delays and pulses. J. Magn. Reson., 99, 99-117 (1992).

70) Kessler, H., Bermel, W., and Griesinger, C., Determination of carbon-carbon connectivities, assignment of quarternary carbons, and extraction of carbon-carbon coupling constants by carbon-relayed hydrogen-carbon spectroscopy. J. Magn. Reson., 62, 573-579 (1985).

71) Lee, K. S., and Morris, G. A., An alternative to the $2 \mathrm{D}$ INADEQUATE experiment for detecting scalar coupling correlations between protonated and unprotonated carbons. Magn. Reson. Chem., 25, 176-178 (1987).

72) Kawabata, J., and Fukushi, E., Application of DEPT C$\mathrm{C}$ relay in spectrum editing by multiplicities of neighboring protonated carbons and accurate determination of ${ }^{13} \mathrm{C}-{ }^{13} \mathrm{C}$ coupling constants. J. Magn. Reson., A107, 173-177 (1994).

73) Kawabata, J., and Fukushi, E., 2D DEPT C $-\mathrm{C}$ relay. Sensitivity enhanced clean two-dimensional C-C COSY without double-quantum filtration. J. Magn. Reson., A117, 88-90 (1995).

74) Fukushi, E., and Kawabata, J., Application of 1D BIRD or X-filtered DEPT long-range $\mathrm{C}-\mathrm{C}$ relay for detection of proton and carbon via four bonds and measuring longrange ${ }^{13} \mathrm{C}-{ }^{13} \mathrm{C}$ coupling constants. Magn. Reson. Chem., 44, 475-480 (2006).

75) Sparks, S. W., and Ellis, P. D., DEPT polarization transfer for the INADEQUATE experiments. J. Magn. Reson., 62, 1-11 (1985).

76) Podkorytov, I. S., Seven-pulse sequence DEPT-INADEQUATE. J. Magn. Reson., 89, 129-132 (1990).

77) Sørensen, O. W., Freeman, R., Frankiel, T., Mareci, T. H., and Schuck, R., Observation of ${ }^{13} \mathrm{C}-{ }^{13} \mathrm{C}$ couplings with enhanced sensitivity. J. Magn. Reson., 46, 180-184 (1982).

78) Fukushi, E., and Kawabata, J., Detection of long-range $J_{\mathrm{CC}}$ by $1 \mathrm{D}$ and $2 \mathrm{D}$ DEPT long-range $\mathrm{C}-\mathrm{C}$ relay. Symposium papers of the 45th Symposium on the chemistry of natural products, 2003, pp. 317-322 (2003).

79) Tsuda, M., Izui, N., Shimbo, K., Sato, M., Fukushi, E.,
Kawabata, J., Katsumata, K., Horiguchi, T., and Kobayashi, J., Amphidinolide X, a novel 16-membered macrodiolide from dinoflagellate Amphidinium sp. J. Org. Chem., 68, 5339-5345 (2003).

80) Koshino, H., and Uzawa, J., Pulsed field gradient ${ }^{15} \mathrm{~N}$ HMBC. Kagaku To Seibutsu (in Japanese), 33, 252-258 (1995).

81) Martin, G. E., and Hadden, C. E., Long-range ${ }^{1} \mathrm{H}_{-}{ }^{15} \mathrm{~N}$ heteronuclear shift correlation at natural abundance. $J$. Nat. Prod., 63, 543-585 (2000).

82) Kawabata, J., Fukushi, E., and Mizutani, J., Sesquiterpene dimers from Chloranthus japonicus. Phytochemistry, 39, 121-125 (1995).

83) Uzawa, J., and Takeuchi, S., Application of selective ${ }^{13} \mathrm{C}-\left\{{ }^{1} \mathrm{H}\right\}$ nuclear Overhauser effects with low-power ${ }^{1} \mathrm{H}$ irradiation in ${ }^{13} \mathrm{C}$ NMR spectroscopy. Org. Magn. Reson., 11, 502-506 (1978).

84) Seto, H., Sasaki, T., Yonehara, H., and Uzawa, J., Studies on the biosynthesis of pentalenolactone. Part I. Application of long range selective proton decoupling (LSPD) and selective ${ }^{13} \mathrm{C}\left\{{ }^{1} \mathrm{H}\right\}$ NOE in the structural elucidation of pentalenolactone G. Tetrahedron Lett., 10, 923-926 (1978).

85) Fukushi, E., Kawabata, J., and Mizutani, J., Discrimination of two methylene groups in non-symmetric succinate esters in sesquiterpene dimers by heteronuclear ${ }^{13} \mathrm{C}\left\{{ }^{1} \mathrm{H}\right\}$ NOE spectroscopy. Magn. Reson. Chem., 33, 909-912 (1995).

86) Krishnamurthy, V. V., Russell, D. J., Hadden, C. E., and Martin, G. E., ${ }^{2} J,{ }^{3} J$-HMBC: a new long-range heteronuclear shift correlation technique capable of differentiating ${ }^{2} J_{\mathrm{CH}}$ from ${ }^{3} J_{\mathrm{CH}}$ correlations to protonated carbons. J. Magn. Reson., 146, 232-239 (2000).

87) Sprang, T., and Bigler, P., A new technique for differentiating between ${ }^{2} J(\mathrm{C}, \mathrm{H})$ and ${ }^{3 / 4} J(\mathrm{C}, \mathrm{H})$ connectivities. Magn. Reson. Chem., 41, 177-182 (2003).

88) Nyberg, N. T., Duus, J. Ø., and Sørensen, O. W., Heteronuclear two-bond correlation: suppressing heteronuclear three-bond or higher NMR correlations while enhancing two-bond correlations even for vanishing ${ }^{2} J_{\mathrm{CH}}$. J. Am. Chem. Soc., 127, 6154-6155 (2005).

89) Kovacs, H., Moskau, D., and Spraul, M., Cryogenic cooled probes-a leap in NMR technology. Prog. Nucl. Magn. Reson. Spectrosc., 46, 131-155 (2005).

90) Martin, G. E., and Hadden, C. E., Comparison of $1.7 \mathrm{~mm}$ submicro and $3 \mathrm{~mm}$ micro gradient NMR probes for the acquisition of ${ }^{1} \mathrm{H}-{ }^{13} \mathrm{C}$ and ${ }^{1} \mathrm{H}-{ }^{15} \mathrm{~N}$ heteronuclear shift correlation data. Magn. Reson. Chem., 37, 721-729 (1999).

91) http://www.geocities.com/ $/$ Shigemi/

92) Takahashi, S., and Nagayama, K., A novel NMR microcell with symmetric geometry. J. Magn. Reson., 76, 347-351 (1988). 